\title{
Incentive reduction: Delay increase and subsequent responding'
}

JAMES H. MCHOSE

Delay of reinforcement in the first goal box $\left(\mathrm{G}_{1}\right)$ of a double alley apparatus was manipulated in two experiments. The results indicated that rats ran faster in the second alley following short as compared with longer delay in $G_{1}$, but delay increase per se had no effects on subsequent performance.

The present paper reports two experiments in a series of studies designed to isolate the class of incentive reductions which facilitate subsequent performance. Previous double alley research has shown that, for a regularly reinforced group, the omission of reward from the first goal box $\left(G_{1}\right)$ on a certain trial (frustrative nonreward) increases second alley $\left(\mathrm{A}_{2}\right)$ speeds on those trials relative to those of a control group never reinforced in $\mathrm{G}_{1}$ (Barrett, Peyser, \& McHose, 1965; Wagner, 1959). A substantial, but incomplete, reduction in $G_{1}$ reward, i.e. to some nonzero magnitude, does not elevate $\mathrm{A}_{2}$ speeds relative to those of a control condition that always receives the reduced magnitude in $\mathrm{G}_{1}$, (Barrett et al, 1965; McHose \& Ludvigson, 1965).

Following Logan's (1960) observation, nonreinforcement on a certain trial for previously reinforced Ss may be viewed as operationally continuous with a simultaneous increase in delay and reduction in magnitude of reinforcement. As noted above, the facilitative effects associated with nonreward are absent with incomplete reductions in reward magintude. Within Logan's framework, the latter observation suggests two possibilities concerning incentive manipulations necessary to facilitate subsequent performance. Previously demonstrated facilitative effects of nonreward may be attributed solely to increases in delay of reinforcement, or, secondly, to the simultaneous increase in delay of reward and decrease in magnitude of reward. The present experiments were concerned with whether an increase in delay of reinforcement in $\mathrm{G}_{1}$ would, like nonreward, facilitate $A_{2}$ performance.

\section{Method}

In Experiment 1, 54 albino male rats received 54 acquisition and 30 postshift trials in an L-shaped double alley apparatus. The apparatus consisted of an 11-in. start box, $\left(\mathrm{S}_{1}\right), 24$-in. alley $\left(\mathrm{A}_{1}\right)$ and an 11 -in. goal box $\left(G_{1}\right)$ and a second 24-in. alley ( $\left.A_{2}\right)$ and 11-in. goal box $\left(G_{2}\right)$, with $G_{1}$ serving as a start box for $A_{2}$. Solenoid-operated, dropping doors separated $S_{1}$ from $A_{1}$ and $G_{1}$ from $A_{2}$. Upward acting retrace doors, normally open, were positioned between $A_{1}$ and $G_{1}$ and $A_{2}$ and $\mathrm{G}_{2}$. A transluscent (clouded) Plexiglas dome formed the top and sides of the entire runway, yielding a 3-1/2 in. base width and 2-1/2 in. apex width. The apex was $4-1 / 2 \mathrm{in}$, above the floor. The clear Plexiglas floor was scribed the width of the alley at $1 / 8 \mathrm{in.}$ intervals through the runway. Two neutral density filters fitted to the second alley dome provided differential first and second alley brightness. A photocell located 1 in. in front of the $G_{1}$ goal cup initiated a timer circuit used to vary the delay of food pellets. Photocell-clock circuitry provided traversal time measures over a $1 \mathrm{ft}$. section of $\mathrm{A}_{2}$ beginning 6 in. from $\mathrm{G}_{1}$.

Fourteen days prior to the first training day Ss were placed on a $23 \mathrm{hr}$. deprivation cycle maintained throughout the experiment. On the two days immediately preceding the first training day, i.e. Days 13 and 14 , Ss received approximately $1 \mathrm{gm}$ of $45-\mathrm{mg}$ Noyes pellets, identical with the subsequent reinforcement pellet, prior to their daily ration. Ss were allowed to explore $S_{1}$ and $A_{1}$ on Days 13 and 14 Each $S$ received one trial on Day 15, 2 trials on Day 16, and 3 trials per day for the remainder of the experiment.

Three groups were randomly constituted and designated according to the delay ( $\mathrm{sec}$.) in $\mathrm{G}_{1}$ on each acquisition trial prior to delivery of three 45-mg pellets: Groups 0, 5 and 15. During the postshift period reinforcement conditions remained identical with acquisition with the following exceptions: Groups 0 and 5 received one "test trial" per day on which $\mathrm{G}_{1}$ delay was increased. For Group 5, this test trial was always a $15 \mathrm{sec}$. delay trial, for Group 0 daily test trials were equally distributed between 5 and $15 \mathrm{sec}$.

In Experiment 2, 23 male albino rats received 72 acquisition and 60 postshift trials in the apparatus described above. Deprivation and pretraining procedures were identical with those of Experiment 1. Each $S$ received 1 trial on Days 15 and 16, 2 trials on Day 17 , and 4 trials per day for the remainder of the experiment.

Three groups were designated according to the delay on each acquisition trial prior to the delivery of two $45-\mathrm{mg}$ pellets: Groups 0 , 15 and 30. During the postshift period Groups 0 and 15 received 2 test trials per 3 day ( 12 trial) period on which $G_{1}$ delay was increased to $30 \mathrm{sec}$. No more than one test trial was given on any one day. All Ss always received 2 pellets immediate reinforcement in $G_{2}$.

In both experiments, the start door separating $G_{1}$ from $A_{2}$ was opened after $S$ had consumed the $G_{1}$ reinforcement and had maintained an orientation toward the door for 3 sec.

\section{Results}

The group mean $A_{2}$ running speeds for each of the various conditions of Experiment 1 are presented in Fig. 1. Within each postshift block for Group 0, mean

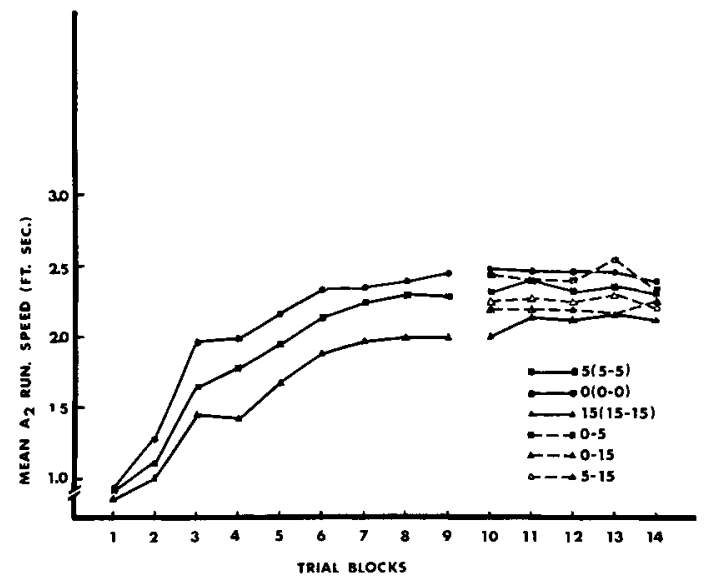

Fig. 1. Mean $A_{2}$ running speeds as a function of trials for the various conditions of $G_{1}$ delay in Experiment 1 . 


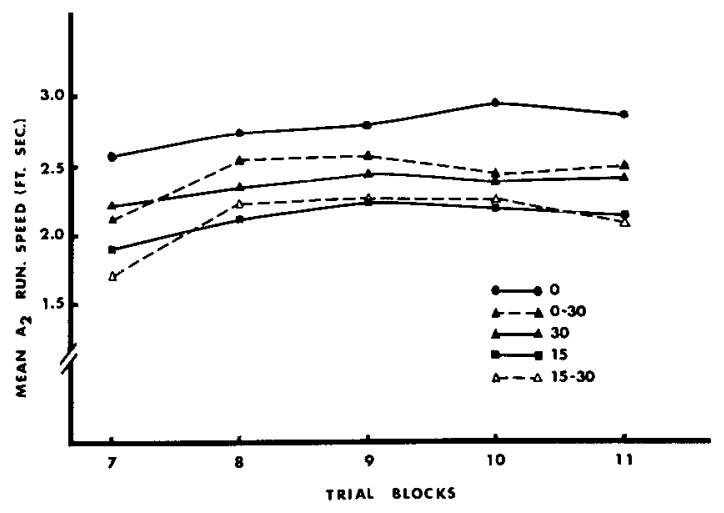

Fig. 2. Mean $A_{2}$ running speeds as a function of postshift trials for the various conditions of $G_{1}$ delay in Experiment 2 .

speeds on $0(0-0), 5(0-5)$, and 15 sec. $(0-15)$ trials are plotted separately. Similarly, speeds for Group 5 on 5 sec, trials (5-5) are plotted separately from those on 15 sec. trials.

As may be seen, $A_{2}$ speeds in acquisition varied inversely with the time of delay of $G_{1}$ reinforcement. Analysis of variance of acquisition speeds over Blocks 7-9 yielded a significant group effect, $F=3.23, \mathrm{df}=2 / 48$, $\mathrm{p}<.05$. Looking next at the postshift period, it will be noted that speeds on test trials for Groups 0 and 5 were decreased relative to those on the acquisition delay value. Variance analyses of mean speeds over Blocks 12-14 for the various Group 0 conditions $(0-0,0-5,0-15)$ yielded a significant conditions effect, $F=9.01, \mathrm{df}=2 / 30$, $\mathrm{p}<.001$. Similarly, analyses of Group 5 performance on 5-5 and 5-15 trials over the same blocks yielded a significant conditions effect, $F=7.29, \mathrm{df}=1 / 18, \mathrm{p}<.025$.

Of particular interest are the comparisons of speeds of Groups 0 and 5 on 15 sec. trials to those for Group 15, since Group 15 serves as a control for isolating the effects of delay increases per se. These analyses, performed individually over Blocks $12-14$, yielded $\mathrm{F}$ ratios less than unity, as did the similar comparison of Group 0 and 5 sec. trials (0-5) with Group 5 on 5 sec. trials.

Postshift group mean $\mathrm{A}_{2}$ speeds for each of the various conditions of Experiment 2 are plotted in Fig. 2. Analyses of variance of speeds over Blocks 10-11 for $0-0,15-15$, and $30-30$, yielded a significant groups effect, $F=7.15, d f=2 / 20, p<.01$. Similarly, Group 0 ran slower over these trial blocks on 30 sec. trials than on 0 sec. delay trials, $F=38.34$, $d f=1 / 7, p<.001$. As may be seen in Fig. 2, 15 and 30 sec. delays resulted in comparable speeds for Group 15. Most important, comparison of the three groups on $30 \mathrm{sec}$.trials over Blocks 10-11 yielded an $F$ ratio less than unity. Thus the increase in delay of $G_{1}$ reinforcements for Groups 0 and 15 had no appreciable effect on speeds relative to those for a control group (Group 30) maintained on the increased delay value.

Discussion

The present results indicate that $\mathrm{A}_{2}$ speeds are inversely related to reinforcement delay time in $\mathrm{G}_{1}$.
This conclusion is supported by comparison between groups regularly receiving differential delay, and by the observation of decreased speeds in $\mathrm{A}_{2}$ within-Ss following increases in delay. The relative performance levels of Groups 15 and 30, (Experiment 2) suggest that the relationship between $A_{2}$ speeds and $G_{1}$ delay is either nonmonotonic or negatively accelerated. It should be noted that these comparisons merely indicate an effect of the reinforcement condition obtained on any trial independent of any change in reinforcement conditions. These absolute or obtained delay effects are in contrast to the effect of "absolute magnitude" in that in the latter case $\mathrm{A}_{2}$ speeds are faster the less the incentive value of $\mathrm{G}_{1}$ reinforcement (Barrett et al, 1965).

The existence of absolute (obtained) delay effects requires that, in assessing relative (training minus obtained) delay effects, comparisons be made between Ss receiving the same delay on a given trial, but differing in training delay value. Such comparisons in the present studies indicate that relative delay, or delay increase, as such has no effect on $\mathrm{A}_{2}$ performance. Thus, in each instance in both experiments, Ss receiving an increased delay on a certain trial displayed $\mathrm{A}_{2}$ speeds comparable to those of Ss trained on and receiving the higher delay.

The present results, in conjunction with those of the magnitude reduction studies (Barrett et al, 1965; McHose \& Ludvigson, 1965) indicate that neither the magnitude decrease nor the delay increase component of frustrative nonreward is alone sufficient to facilitate subsequent performance. This functional disparity occurs despite the fact that the amounts of (incomplete) magnitude reduction in previous studies have been comparable to those typically employed in experiments demonstrating the facilitative effects of frustrative nonreward. In this connection, the present delay values have encompassed the probable $\mathbf{G}_{1}$ detention times on non-rewarded trials in the frustrative nonreward literature (cf. McHose, 1963; Wagner, 1959).

\section{References}

Barrett, R. J., Peyser, C. S., \& McHose, J. H. Effects of complete and incomplete reward reduction on a subsequent response. Psychon. Sci., 1965, 3, 277-278.

Logan, F. A. Incentive. New Haven: Yale University Press, 1960. McHose, J. H. The effect of continued nonreinforcement on the frustration effect. J. exp. Psychol., 1963, 65, 444-451.

Mcllose, J. H., \& Ludvigson, H. W. The role of reward magnitude and incomplete reduction in reward magnitude in the frustration effect. $J$. exp. Psychol., 1965, 70, 490-495.

Wagner, $\mathbf{A}$. R. The role of reinforcement and nonreinforcement in an "apparent frustration effect". J. exp. Psychol., 1959, 57, $130-136$.

\section{Note}

1. Supported by grant MH- 10340 from the United States Public Health Service. Data from Experiment 1 were originally reported by the author and H. W. Ludvigson at the 1965 convention of the Midwestern Psychological Association. 